\title{
SUSTENTABILIDADE ORGANIZACIONAL NA ITAIPU BINACIONAL: UMA ANÁLISE DE SEUS NIVEIS
}

\section{NADIESSA CAPPELLARI}

Mestra em Administração, Universidade Estadual do Centro-Oeste - UNICENTRO, Brasil. Gerente Operacional no Itaú Unibanco, Brasil. nadiessa.cappellari@hotmail.com

\section{Silvio Roberto Stefano}

Pós-Doutor em Administração, Universidade do Vale do Itajaí - UNIVALI, Brasil.

Professor associado da Universidade Estadual do Centro-Oeste - UNICENTRO, Brasil.

Professor do Mestrado Profissional em Administração da Universidade Estadual do Centro-Oeste - UNICENTRO, Brasil.

professor-silvio@hotmail.com

\section{MARCOS DECASTRO}

Doutor em Administração, Universidade Federal do Paraná - UFPR, Brasil.

Professor do Mestrado Profissional em Administração, Universidade Estadual do Centro-Oeste - UNICENTRO, Brasil.

marcosdecastroms@yahoo.com.br

\section{Resumo}

Este trabalho teve como objetivo principal compreender os niveis de sustentabilidade organizacional na Itaipu Binacional. Quanto à metodologia, esta pesquisa se caracteriza como qualitativa, com fins descritivos e utilizando a estratégia de estudo de caso. A coleta de dados ocorreu por meio de entrevistas semiestruturadas com 12 funcionários, observação não participante, diário de pesquisa, além de documentos e registros em arquivos. Verificou-se que a Itaipu Binacional se destaca na geração de energia renovável e que seu modelo de operação sustentável e gestão participativa visam ao respeito à natureza e qualidade de vida para as futuras gerações. A Itaipu integrou a sustentabilidade em seus pressupostos estratégicos e apresenta um sistema de gestão que permeia todo o ambiente organizacional e níveis hierárquicos, e, por conseguinte, pode ser classificado no nível de sustentabilidade organizacional holística, como proposto por Van Marrewijk (2010).

Palavras-chave: sustentabilidade organizacional, nível de sustentabilidade organizacional, gestão socioambiental. 


\title{
ORGANIZATIONAL SUSTAINABILITY AT ITAIPU BINACIONAL: AN ANALYSIS OF ITS LEVELS
}

\begin{abstract}
This paper aims at understanding the levels of organizational sustainability at Itaipu Binacional. Regarding the methodology, this research is characterized as qualitative, with descriptive purposes and using the case study strategy. Data collection took place through semi-structured interviews with 12 employees, non-participant observation, research diary, as well as documents and records. The results showed that Itaipu Binacional stands out in the generation of renewable energy, and that its sustainable operation model and participatory management aim to respect nature and quality of life for future generations. Itaipu has integrated sustainability into its strategic assumptions and presents a management system that permeates the entire organizational environment and hierarchical levels and can therefore be classified at the level of holistic organizational sustainability as proposed by Van Marrewijk (2010).
\end{abstract}

Keywords: organizational sustainability, organizational sustainability level, socio-environmental management.

\section{SOSTENIBILIDAD ORGANIZACIONAL EN ITAIPÚ BINACIONAL: UN ANÁLISIS DE SUS NIVELES}

\begin{abstract}
Resumen
Este trabajo tuvo como objetivo principal comprender los niveles de sustentabilidad organizacional en Itaipu Binacional. En cuanto a la metodología, esta investigación se caracteriza como cualitativa, con fines descriptivos y utilizando la estrategia de estudio de caso. La recolección de datos ocurrió a través de entrevistas semiestructuradas con 12 funcionarios, observación no participante, diario de investigación, además de documentos y registros en archivos. Se verificó que la Itaipu Binacional se destaca en la generación de energía renovable, y que su modelo de operación sustentable y gestión participativa apunta el respeto a la naturaleza y calidad de vida para las futuras generaciones. Itaipu integró la sustentabilidad en sus presupuestos estratégicos y presenta un sistema de gestión que permea todo el ambiente organizacional y niveles jerárquicos, y por lo tanto puede clasificarse en el nivel de sostenibilidad organizacional holística, como propuso por Van Marrewijk (2010).
\end{abstract}

Palabras clave: sustentabilidad organizacional; nivel de sustentabilidad organizacional; gestión socioambiental. 


\section{INTRODUÇÃO}

O cenário atual é caracterizado por diversas crises provenientes do aquecimento global, da diminuição da camada de ozônio, do esgotamento de recursos naturais, da extinção da fauna e da flora, do derretimento das calotas polares, das chuvas ácidas, entre outros, que têm limitado a capacidade de resiliência dos ecossistemas. Inseridas neste contexto, empresas de geração de energia têm repensado seus modelos de gestão, pois estão entre os setores que mais provocam impactos ambientais (Braga, Silva, \& Santos, 2015). No Brasil, a capacidade de geração energética é distribuída da seguinte forma: $64,30 \%$ energia hidráulica, $27,42 \%$ energia térmica, 6,62\% energia eólica, e, 1,66\% de fontes alternativas, tais como biocombustiveis e energia nuclear, entre outros (Aneel, 2016).

Preocupando-se com a continuidade da vida agora e no futuro, muitas dessas empresas, como a Itaipu, estão adotando uma postura em busca do desenvolvimento sustentável (DS). A sociedade está sendo instigada a repensar suas ações, buscando atitudes que preservem o planeta e propiciem melhorias nos padrões de qualidade de vida, como a erradicação da pobreza e distribuição equitativa dos recursos (Hopwood, Mellor, \& O’Brien, 2005).

Foi por meio do relatório Brundtland, elaborado pelo World Commissionon Environmentand Development (WCED) em 1987, que emergiu a principal definição do tema: o desenvolvimento que responde às necessidades do mundo atual sem comprometer a capacidade das gerações futuras de terem suas necessidades atendidas (WCED, 1987). Este documento é considerado o mainstream da literatura moderna e apresenta os caminhos para que o DS ocorra em nível global e organizacional (Blowfield, 2013).

Apesar do reconhecimento de sua importância, os avanços no campo do DS têm acontecido de forma lenta, com dificuldades de operacionalização (Soparnot, 2011). Neste sentido, as pesquisas de Blowfield (2013), Dyllick e Horckerts (2002) e Munck (2013) apontam as organizações empresariais como tendo um importante papel nesse cenário. A sustentabilidade organizacional (5O) pode ser definida como o encontro às necessidades dos stakeholders diretos e indiretos, sem que a capacidade de sustentar necessidades futuras seja comprometida (Munck, 2013). Por meio dela, as organizações são incentivadas a contribuírem com o DS, buscando o equilíbrio nos aspectos ambientais, sociais e econômicos (Elkington, 2011). Esses pressupostos formam e sustentam os três pilares da sustentabilidade organizacional - econômico, social e ambiental -, apresentados por Elkington (2011) como triple bottom line (TBL).

Sachs (2008) também contribui com o tema levantando que se faz necessário ter uma visão holística dos problemas da sociedade e apresenta os cinco pilares do DS, sendo eles o social, o ambiental, o territorial, o econômico e o político. Esse novo paradigma faz com que cada organização desenvolva princípios sustentáveis alinhados aos seus sistemas de valores, objetivos e estratégias. Neste contexto, muitas organizações incorporam a $\mathrm{SO}$ em seu planejamento estratégico, contemplando-a tanto na cultura como nas atividades organizacionais. Elas realinham suas ações pautadas por novos valores, modificam sua missão, visão e políticas, refletindo sua conformidade às exigências atuais e futuras (Stefano \& Alberton, 2015).

Com vistas a identificar os patamares de $\mathrm{SO}$ em que as organizações se encontram, Van Marrewijk (2010) propôs a "matriz de sustentabilidade", uma ferramenta que abarca cinco níveis de sustentabilidade, dispostos de maneira hierárquica e crescente em relação à complexidade, que ajuda a classificar as empresas por meio de suas práticas.

OS, Organizações e Sustentabilidade, 6(2), p. 42-58, Londrina, PR, jul./dez. 2018, 
A utilização da matriz de sustentabilidade permite que as organizações avaliem estrategicamente 0 resultado de suas práticas, servindo de parâmetro para aferir o nível de suas ações. Em cada nível, novas práticas são implementadas, o que pode conduzir a um desenvolvimento institucional correspondente à sua ambição pelo equilíbrio das questões sociais, ambientais e econômicos (Borca, C., Maria, L., Sirbu, R., \& Fistis, G., 2015).

Observa-se, assim, que muitas organizações estão atentas às demandas, que vão além das funções básicas de planejamento, organização e controle, passando a se preocupar com questões relacionadas à responsabilidade social, desempenho ambiental correto e controle dos impactos das atividades, produtos e serviços (Porter \& Kramer, 2006). Com o apoio e conhecimento da visão do negócio pelos colaboradores, se fortalece uma cultura voltada à sustentabilidade e se internalizam novos valores e atitudes, minimizando os impactos socioambientais negativos gerados pela rotina de trabalho e de vida (Carvalho, Stefano, \& Munck, 2015).

Como exemplo de organização que procura integrar os pressupostos sustentáveis a suas ações, encontra-se a Itaipu Binacional, que é responsável pela construção e gestão da usina e tem relevância estratégica para os sistemas elétricos do Brasil e Paraguai. A empresa se destaca por suas ações de educação e transformação socioambiental, atuando na qualidade de vida de sua região de influência, principalmente dos 29 municípios brasileiros nela contidos (Filho, Sedor, Finck, \& Asanome, 2011). Ela também possui práticas de sustentabilidade estabelecidas e reformulou sua estratégia motivada em princípios e valores da sustentabilidade (Itaipu, 2016a).

Partindo do pressuposto que a Itaipu Binacional desenvolve ações voltadas para a sustentabilidade organizacional e considerando a relevância dos temas debatidos para a sociedade atual, apresentase o seguinte problema de pesquisa: qual o nivel de sustentabilidade organizacional na Itaipu Binacional e como suas práticas se encontram atualmente? Desta forma, tem-se como objetivo principal compreender os niveis de sustentabilidade organizacional na Itaipu Binacional.

A estrutura deste artigo envolve o quadro teórico, com a discussão de sustentabilidade organizacional e a matriz da sustentabilidade, a metodologia, com o detalhamento dos procedimentos de pesquisa, e as análises dos resultados e considerações finais.

\section{QUADRO TEÓRICO}

\section{SUSTENTABILIDADE ORGANIZACIONAL}

Os conceitos de desenvolvimento sustentável (DS) e sustentabilidade organizacional (SO) são expressões globalmente conhecidas que têm mobilizado diferentes instituições pelo princípio comum de alcançá-los. No entanto, esses temas são carentes de um quadro teórico consolidado, dificultando sua aplicabilidade e compreensão. Inicia-se, portanto, esta investigação esclarecendo os seus principais conceitos.

Sachs (2008, p.15-16) contribui com o tema apresentando os cinco pilares do DS:

a) social, é fundamental por motivos tanto intrínsecos quanto instrumentais por causa da perspectiva de disfunção social que paira de forma ameaçadora sobre muitos lugares problemáticos do planeta;

b) ambiental, com as suas duas dimensões (os sistemas de sustentação da vida como provedores de recursos e como recipientes para disposição de resíduos);

c) territorial, relacionado à distribuição espacial dos recursos, das populações e das atividades;

d) econômico, sendo a viabilidade econômica a conditio sine qua non para que as coisas aconteçam; 
e) político, a governança democrática é um valor fundador e um instrumento necessário para fazer as coisas acontecerem; a liberdade faz toda a diferença (Sachs, 2008, p.15-16).

Entende-se que o tema vem promovendo transformações no modo de vida das pessoas, levando à construção de um conjunto de princípios, normas e leis que orientem os indivíduos e as organizações a assumirem comportamentos mais responsáveis (Hopwood, Mellor, \& O’Brien, 2005). Esse novo posicionamento busca promover a igualdade e maximizar as vantagens das classes sociais desfavorecidas, reduzindo os niveis de pobreza global. Valores como igualdade, equidade e solidariedade também estão relacionados ao conceito (Sachs, 2008).

Dentro deste contexto, a SO tem o papel de incentivar as corporações a contribuir com o DS. Ela pode ser definida como "o encontro das necessidades dos stakeholders diretos e indiretos (funcionários, clientes, comunidades, grupos de pressão) sem que a capacidade de sustentar necessidades futuras seja comprometida" (Munck, 2013, p. 31). O índice Dow Jones de sustentabilidade define SO como a abordagem de negócios que cria valor de longo prazo para os acionistas, ao vislumbrar oportunidades de gerenciar os riscos decorrentes da evolução econômica, ambiental e social (Blowfield, 2013)

Nesse sentido, as organizações são desafiadas a inovar constantemente, mudando a ênfase do crescimento econômico (com foco na quantidade) para o desenvolvimento sustentável (com foco nas qualidades econômicas, ambientais e sociais), considerando as três dimensões da sustentabilidade, o Triple Botton Line (TBL) ou "Tripé da Sustentabilidade". Essa abordagem também é conhecida como três P's (People, Planet, Profit), pois enfatiza aspectos como lucro, desenvolvimento social e preservação ambiental. Essas discussões são idealizadas por Elkington (2011) na obra "Canibais com Carfo e Faca", em que ele apresenta o relacionamento entre as organizações e as pessoas envolvidas em seus negócios, uma vez que os indivíduos são capazes de influenciar a abordagem da sustentabilidade.

Embora a sustentabilidade seja uma tendência global, muitas empresas ainda não estão engajadas nesse novo contexto, o que pode prejudicar a sobrevivência em um cenário de complexa concorrência mundial. Para Elkington (2011), o sucesso futuro das organizações vai depender da sua habilidade de satisfazer não apenas o objetivo da lucratividade, mas também da qualidade ambiental e da justiça social. A transição para a sustentabilidade exigirá a reestruturação das organizações, com stakeholders engajados em uma visão clara do futuro, atuando de maneira eficiente e eficaz nos três pilares do TBL (Blowfield, 2013; Elkington, 2011).

No entanto, muitas organizações ainda relutam em operacionalizar a SO devido aos investimentos que podem ser requeridos. Além dos dispêndios financeiros, ela pode ser considerada como entrave moral, ação filantrópica, exigência legal ou até mesmo um mal necessário para sua legitimidade perante a sociedade (Carvalho, Stefano, \& Munck, 2015). Porter e Kramer (2006) alertam que a sustentabilidade ainda não é tratada como oportunidade de negócios, para aumento de rendimentos e diminuição de custos e riscos.

Com vistas a identificar os patamares de $\mathrm{SO}$ em que as organizações se encontram, Van Marrewijk (2010), com base nos trabalhos de Van Marrewijk e Werre (2003), desenvolveu a "matriz de sustentabilidade". Essa ferramenta abarca cinco niveis de sustentabilidade dispostos de maneira hierárquica e crescente em relação à complexidade. Cada um dos níveis implica práticas organizacionais distintas, conforme pode ser observado no Quadro 1. 
QUADRO 1 - MATRIZ DA SUSTENTABILIDADE

\begin{tabular}{|c|c|}
\hline Nivel & Descrição \\
\hline $\begin{array}{l}\text { 1. } 50 \text { em } \\
\text { conformidade } \\
\text { com a legislação }\end{array}$ & $\begin{array}{l}\text { Almeja proporcionar bem-estar para a sociedade, dentro dos limites e regulamentos das } \\
\text { autoridades de direito. Além disso, as organizações podem agir por caridade e responsabilidade. A } \\
\text { SO é percebida como um dever e obrigação, ou como o comportamento correto. }\end{array}$ \\
\hline $\begin{array}{l}\text { 2. SO orientada } \\
\text { pelo lucro }\end{array}$ & $\begin{array}{l}\text { Consiste na integração dos aspectos sociais, éticos e ambientais em operações de negócios e } \\
\text { tomada de decisão, desde que contribuam com os objetivos financeiros. É motivado pela } \\
\text { rentabilidade e melhoria da reputação em vários mercados (clientes / empregados / acionistas). }\end{array}$ \\
\hline $\begin{array}{l}\text { 3. SO consciente } \\
\text { conservadora }\end{array}$ & $\begin{array}{l}\text { Procura equilibrar as preocupações econômicas, sociais e ambientais, com o mesmo grau de } \\
\text { importância. Suas iniciativas vão além da conformidade legal e do objetivo da lucratividade. } \\
\text { Considera o potencial humano, a responsabilidade social e os cuidados com o planeta importantes. }\end{array}$ \\
\hline 4. 50 sinérgica & $\begin{array}{l}\text { Busca por soluções equilibradas e funcionais, criando valor nos aspectos econômicos, sociais e } \\
\text { ambientais da organização, em uma abordagem sinérgica, onde todas as partes interessadas } \\
\text { ganham em conjunto. Acredita que a sustentabilidade é crucial e inevitável para alcançar o } \\
\text { progresso. }\end{array}$ \\
\hline 5. SO holística & $\begin{array}{l}\text { A SO é totalmente integrada e incorporada em todos os aspectos da organização, visando } \\
\text { contribuir para a qualidade e a continuação da vida, agora e no futuro. Sua motivação é a de que a } \\
\text { sustentabilidade é a única alternativa uma vez que todos os seres e fenômenos são mutuamente } \\
\text { interdependentes. Cada pessoa ou organização, portanto, tem uma responsabilidade universal } \\
\text { para com todos os outros seres. }\end{array}$ \\
\hline
\end{tabular}

Fonte: Adaptado de Van Marrewijk (2010).

As organizações tendem a adotar o nivel de $\mathrm{SO}$ que mais bem se ajuste aos seus objetivos, estratégias e níveis de racionalidade, como demonstra o Quadro 1. Cada abordagem caracteriza um nivel de desenvolvimento específico, transcendendo e incluindo os antigos, cada uma apoiada em seus sistemas de valores e paradigmas de gestão, coerentes com as estruturas institucionais (Van Marrewijk, 2010). Logo, estar em niveis mais altos de sustentabilidade não significa que estas organizações sejam as melhores, mas sim que sua complexidade é diferenciada (Van Marrewijk \& Werre, 2003).

Diante do exposto, constata-se que, atualmente, as organizações passaram a competir pela legitimidade relacionada à mudança de postura, tornando a sustentabilidade uma nova demanda institucional (Garrido \& Saltorato, 2015). Elas estão atentas às demandas, que vão além das funções básicas de planejamento, organização e controle, passando a se preocupar com questões relacionadas à responsabilidade social, desempenho ambiental correto e controle dos impactos das atividades, produtos e serviços (Porter \& Kramer, 2006). Com apoio e conhecimento da visão do negócio pelos colaboradores, se fortalece uma cultura voltada à sustentabilidade e se internalizam novos valores e atitudes, minimizando os impactos socioambientais negativos gerados pela rotina de trabalho e de vida (Carvalho, Stefano, \& Munck, 2015).

\section{PROCEDIMENTOS METODOLÓGICOS}

Nesta pesquisa foi investigada a Itaipu Binacional, que é juridicamente internacional e responsável pela construção e gestão da usina. A empresa selecionada procura integrar os pressupostos sustentáveis a suas ações e se destaca pelas ações de educação e transformação socioambiental, que estão mudando a qualidade de vida de sua região de influência (Filho, Sedor, Finck, \& Asanome, 2011).

No que se refere à classificação geral, esta pesquisa se caracteriza como qualitativa com fins descritivos e utiliza a estratégia de estudo de caso. A pesquisa foi qualitativa, considerando o interesse por aprofundar o conhecimento sobre um caso específico, neste caso compreender o nível de sustentabilidade organizacional da usina a partir ponto de vista dos informantes (Denzin \& Lincoln, 2006, p. 16). Quanto aos fins, é descritivo, uma vez que os dados coletados foram apresentados por meio de transcrições de entrevistas e anotações de campo. Também é um estudo 
de caso único, indicando "uma investigação empírica que aborda fenômenos contemporâneos em profundidade e em seu contexto de vida real" (Yin, 2010, p. 39).

Com relação à perspectiva temporal, o estudo se caracteriza como pesquisa de dados transversais, uma vez que seus elementos são investigados somente no mês de setembro de 2016 (Babin, B., Hair Jr., J. F., Money, A. H., \& Samouel, P., 2005). As pessoas participantes foram selecionadas de acordo com o posicionamento hierárquico (estratégico, tático, operacional), sendo aquelas que atuassem diretamente com a gestão ambiental, social e econômica e pudessem fornecer as informações necessárias para responder aos objetivos deste trabalho. Levaram-se em conta também as condições de acesso proporcionadas pelos responsáveis da empresa.

No estudo de caso, foram utilizadas quatro fontes (técnicas) de coleta como forma de obter detalhes em profundidade: (a) entrevistas semiestruturadas, (b) observação (não participante), (c) diário de pesquisa e (d) documentos e registros em arquivos.

As entrevistas foram conduzidas com uma amostra de 12 funcionários, denominados por meio de letras maiúsculas do alfabeto, de entrevistado "A" a "L", nos escritórios de Curitiba e Foz do lguaçu. 0 roteiro semiestruturado foi composto por informações sobre o perfil dos respondentes (sexo, telefone, e-mail, formação acadêmica, função atual, tempo de trabalho) e por questões relacionadas ao nível de sustentabilidade organizacional da empresa, construídas a partir do referencial teórico deste trabalho. As entrevistas foram gravadas e posteriormente transcritas com o consentimento prévio dos entrevistados, que assinaram um termo de consentimento livre e esclarecido. As gravações tiveram duração total de nove horas e quarenta e oito minutos.

Já a observação não participante foi realizada durante as visitas à Itaipu Binacional, objeto desta pesquisa, para compreender as práticas, as interações e os eventos que envolvem as ações de sustentabilidade organizacional (Bardin, 2016). O diário de pesquisa, por sua vez, foi utilizado durante a observação realizada na empresa, bem como nas entrevistas com os sujeitos da investigação. As fontes secundárias foram definidas como documentos e registros em arquivos, sendo considerados os materiais informativos da empresa, livros próprios, revistas especializadas, os relatórios de sustentabilidade, sites da organização e pesquisas já realizadas na usina. A análise desses documentos teve como finalidade levantar informações e ampliar a compreensão de fatos e objeto temporal, social, histórico e cultural do foco estudado.

As categorias de análise se referem aos constructos, que são objetos de estudo na pesquisa (Bauer \& Gaskell, 2015). Para que a pesquisa atinja os objetivos propostos, é necessário categorizar as informações fundamentais para a conclusão do trabalho. As categorias de análise deste estudo foram criadas a partir dos niveis de sustentabilidade organizacional propostos por Van Marrewijk (2010), sendo elas SO consciente/conservadora, SO sinérgica e SO holística (nível de sustentabilidade organizacional).

Por fim, o tratamento, análise e interpretação das evidências foram realizados por meio da técnica de análise de conteúdo. Para Bardin (2016, p. 44), a análise de conteúdo representa "um conjunto de técnicas de análise das comunicações, que utiliza procedimentos sistemáticos e objetivos de descrição do conteúdo das mensagens". Também foi realizada a triangulação dos dados por meio de entrevistas com funcionários, diário de pesquisa, análise documental, relatórios, sites, pesquisas anteriores, observação não participante, entre outros, relacionando com a literatura abordada. Primeiramente, os dados foram separados e depois categorizados de acordo com a fundamentação teórica, condizentes com os objetivos deste trabalho. Na sequência foram escolhidos os documentos e os entrevistados que compuseram a base de dados para o estudo. Posteriormente, o material foi lido e organizado, constituindo os indicadores para fundamentar a interpretação. As categorias foram utilizadas para inferência e, posteriormente, interpretação e análise, oferecendo elementos para as considerações finais.

OS, Organizações e Sustentabilidade, 6(2), p. 42-58, Londrina, PR, jul./dez. 2018, 


\section{ANÁLISE DE DADOS E RESULTADOS}

\section{CARACTERIZAÇÃo do OBjeto de EstUdo}

A Itaipu foi responsável pela construção e gestão da usina, construída no período de 1975 a 1982. Ela foi criada e é regida pelo tratado de Itaipu, assinado em 26 de abril de 1973. A usina está localizada no Rio Paraná, na fronteira entre o Brasil (Foz do Iguaçu) e o Paraguai (Hernandárias). As sedes estão nas cidades de Brasília e Assunção e há escritórios em Curitiba, Foz do Iguaçu, Guaíra, Santa Helena, São Paulo e Cidade de Leste (Itaipu, 2016a).

A organização se destaca como importante fonte hidráulica para geração de energia renovável. Em três décadas de operação, sua produção já ultrapassou 2,2 bilhões de megawatts-hora (MWH), energia suficiente para suprir o consumo de toda a Terra durante 37 dias. Tais resultados Ihe conferem liderança mundial em produção acumulada de energia limpa e renovável. Em 2015 sua produção foi 1,6\% maior que a do ano anterior e 2,5\% maior que a registrada pela hidrelétrica chinesa Três Gargantas (Itaipu, 2016a).

Nos últimos 12 anos, busca integrar os pressupostos de sustentabilidade em sua gestão. Assim, reformulou sua estratégia empresarial, alinhando excelência operativa, desenvolvimento socioeconômico e responsabilidade socioambiental em um mesmo patamar de importância. Para atingir os objetivos organizacionais, a empresa alinhou missão, visão e política a fim de assegurar que os novos valores se institucionalizassem (Itaipu, 2016a).

Destaca-se que as iniciativas adotadas pela Itaipu são de caráter voluntário, uma vez que ela é regida por um tratado internacional e obedece a um sistema de gestão diferenciado, devendo se submeter às exigências desse normativo. No entanto, as ações da usina procuram estar alinhadas às obrigações previstas na legislação brasileira e paraguaia e envida esforços para atender os requisitos previstos em tais legislações em todas suas unidades operacionais (entrevistado J).

Assim, a usina se sobressai pela promoção de iniciativas sustentáveis, servindo de inspiração para que empresas nacionais, internacionais e a comunidade com a qual se relaciona assumam uma postura mais ética e responsável nos negócios, contribuindo com a qualidade econômica e socioambiental para as futuras gerações.

\section{Análises do Nivel de Sustentabilidade Organizacional}

Estudos indicam que a SO demonstra ser mais eficiente quando integrada à estratégia organizacional (Munck, 2013). Esse é um processo desafiador, que pode ser viabilizado por meio da alteração das estruturas e práticas organizacionais e do alinhamento da missão, visão e políticas aos valores institucionais (Orsato, 2012).

Nessa perspectiva, com vistas a identificar os patamares de $\mathrm{SO}$ em que as organizações se encontram, Van Marrewijk (2010), com base nos trabalhos de Van Marrewijk e Werre (2003), desenvolveu a "matriz de sustentabilidade". Essa ferramenta abarca cinco niveis de sustentabilidade dispostos de maneira hierárquica e crescente em relação à complexidade. Cada um dos niveis implica práticas organizacionais distintas, a saber: $\mathrm{SO}$ em conformidade com a legislação, SO orientada pelo lucro, SO consciente conservadora, SO sinérgica e SO holística.

Cada abordagem representa um nível de desenvolvimento específico, incluindo e transcendendo o anterior, apoiado em sistemas de valores e paradigmas de gestão coerentes com as estruturas organizacionais. Assim, as empresas tendem a adotar o nivel de $\mathrm{SO}$ que melhor se ajuste aos seus objetivos, estratégias e níveis de racionalidade (Van Marrewijk, 2010).

OS, Organizações e Sustentabilidade, 6(2), p. 42-58, Londrina, PR, jul./dez. 2018, 
Considerando que a Itaipu Binacional possui práticas de $\mathrm{SO}$ estabelecidas e tem inspirado organizações de todo mundo a repensarem suas ações de maneira mais ética e responsável, investigou-se em qual nivel de SO a usina se encontra. Foram analisados apenas os três últimos niveis da matriz de Van Marrewijk (2010), pois as evidências coletadas durante as observações, análise documental e entrevistas indicaram que as práticas utilizadas pela Itaipu transcendem questões de conformidade legal e de orientação pelo lucro, como propostos nos dois primeiros níveis da matriz.

\title{
Nivel de Sustentabilidade Organizacional Consciente e/ou Conservadora
}

O nivel de sustentabilidade organizacional consciente e/ou conservadora é o terceiro em hierarquia na matriz de sustentabilidade. Nele se encontram as organizações que procuram equilibrar as preocupações econômicas, sociais e ambientais, como apregoa o princípio do TBL proposto por Elkington (2011). As iniciativas deste nivel devem ir além da conformidade legal e do objetivo da lucratividade, como apresentado nos dois primeiros níveis (Van Marrewijk, 2010).

Nesta abordagem, questões como a importância do potencial humano, a responsabilidade social e os cuidados com o planeta devem ser consideradas nas decisões estratégicas. Assim, os principais valores abordados são consenso, prevenção de conflitos, trabalho em equipe, igualdade, participação, honestidade e transparência (Van Marrewijk, 2010).

Atendendo às orientações desta subcategoria, os respondentes foram questionados se as iniciativas sustentáveis da Itaipu vão além da conformidade legal e do objetivo da lucratividade. Inicialmente, o entrevistado J ressaltou que a usina não é orientada pelo lucro, pois "tem uma natureza jurídica diferenciada, onde precisa basicamente equilibrar custos e receitas" (Entrevistado J). No que é pertinente à legislação, "a Itaipu segue o Tratado da Itaipu, que é como se fosse sua própria lei. Então a gente diz que a Itaipu faz além da lei de forma voluntária” (Entrevistado J).

Os dados fornecidos pelos entrevistados coincidem com as informações obtidas no relatório de sustentabilidade de 2013, em que fica evidenciado que a usina realiza espontaneamente uma série de iniciativas que beneficiam a comunidade, uma vez que ela é regida por um tratado internacional e legalmente deve se submeter às exigências desse normativo:

\begin{abstract}
Desde a época da sua construção, a Itaipu realiza espontaneamente uma série de iniciativas que beneficiam a região oeste do Paraná e a população da Tríplice Fronteira (Brasil, Argentina e Paraguai). No planejamento e execução das ações, a empresa adota como referência diversos acordos, tratados e convenções nacionais e mundiais, como o Pacto Global das Nações Unidas e a Carta da Terra, e também busca cooperar com o fortalecimento das políticas públicas estabelecidas pelo Governo Federal para o enfretamento de problemas regionais (Itaipu, 2016a, p. 55).
\end{abstract}

Pode-se observar que os funcionários da Itaipu compreendem que as ações de sustentabilidade realizadas transcendem as exigências legais e o objetivo da lucratividade. O entrevistado $F$ reforça:

\footnotetext{
... eu sei que vão. Aliás, lucratividade aqui não é o objetivo. A empresa foi concebida para gerar energia a preço de custo para seus donos, com alguns benefícios financeiros definidos, e não para gerar resultado da forma clássica. 0 respeito mútuo a esse espírito de cooperação é o que viabiliza essa parceria entre dois países de dimensões tão distintas. (Entrevistado F)
}

Esclarecidos os aspectos de conformidade legal e do objetivo da lucratividade, foi verificado se a usina trata os aspectos sociais, ambientais e econômicos com equidade. Essa questão gerou divergência. Alguns entrevistados entendem que o aspecto ambiental se sobressai: "o ambiental é mais forte e recebe mais atenção, ou então explora melhor essa questão de comunicação" (Entrevistado J). Outros acreditam que seja o econômico: "eu defendo que o lucro que financia as benesses ambientais e gera excedente para os reinvestimentos econômicos. Abrir mão do lucro seria 
insano. A humanidade precisa fazer com que o lucro conviva com todo esse respeito que é a ética da sustentabilidade" (Entrevistado G). No entanto, mesmo com algumas opiniões diferenciadas, os funcionários entendem que a Itaipu promove ações nas três áreas do TBL.

Essa perspectiva é reforçada pelo entrevistado C, que comenta que é necessário um olhar mais aprofundado sobre as ações realizadas. Segundo ele, muitos programas classificados como ambientais também apresentam benefícios sociais e econômicos, e vice-versa. Isso demonstra que os aspectos do TBL se inter-relacionam e se retroalimentam, sendo difícil dissociá-los um dos outros.

O entrevistado G destacou que as organizações deveriam sair da ética de mercado (consumista, extrativista) para perseguir a ética da sustentabilidade, que preza pelo equilíbrio entre as dimensões. Essa opinião acompanha o pensamento de Elkington (2011), quando defende que a sociedade deve mudar a ênfase de crescimento econômico, geralmente o grande objetivo das organizações capitalistas, para desenvolvimento sustentável (com foco nas qualidades econômica, ambiental e social).

Por fim, o entrevistado / salienta que o tema é muitas vezes trabalhado de forma fragmentada, o que pode representar um desafio a ser superado:

\footnotetext{
... um dos desafios que eu vejo seja tratar a sustentabilidade de maneira fragmentada. Por exemplo, na diretoria financeira, eles cuidam de coisas que entendem que seja da diretoria deles. Só que se eles ampliarem o olhar, vão ver que contribuem para o meio ambiente, contribuem para o social e talvez isso não esteja muito claro ainda. Com essa visão fragmentada se perde muito, eu acho (Entrevistado J).
}

Evidencia-se, por meio das respostas obtidas, que existem divergências de opiniões em relação à igualdade de importância com que são tratados os aspectos do TBL. Enquanto alguns acreditam que o ambiental seja o mais valorizado, outros consideram o econômico como o mais perseguido. No entanto, a maioria entende que a usina está no caminho do equilíbrio e apresenta preocupações sociais, ambientais e econômicas. Esse resultado também representa uma das principais críticas associadas à teoria da SO: a sua dificuldade de mensuração e operacionalização, ou seja, avaliar e quantificar quanto cada aspecto é trabalhado (Munck, 2013).

O entrevistado F afirma que "hoje, já não é mais possivel delimitar as ações entre o que é sustentabilidade e o que não é, porque a transversalidade do conceito permeia todas as ações do plano operacional, que é o conjunto de tudo que a empresa executa no dia a dia". Assim, a partir das observações realizadas em campo e da análise das entrevistas, percebeu-se que a usina demonstra preocupação com três as dimensões a fim de cooperar com o desenvolvimento de médio e longo prazo. Embora seja difícil mensurar qual dos aspectos ganhe mais atenção, todos eles recebem iniciativas determinadas. Inclusive, a própria usina incentiva a transversalidade dos temas, em que uma área complemente a outra, reforçando a interconexão dos pilares. Cabe também destacar que a empresa em estudo objetiva o equilíbrio financeiro, e não o lucro, e que, desde o início de suas atividades, manifestou preocupação com o entorno.

Esses resultados denotam que a Itaipu Binacional está no nível de sustentabilidade organizacional consciente e/ou conservadora, uma vez que atende aos requisitos propostos pela categoria. Concluída a análise do terceiro nível de SO, parte-se para a SO sinérgica.

\section{Nivel de Sustentabilidade Organizacional SinÉRgica}

O nível de sustentabilidade organizacional consciente e/ou conservadora é o terceiro em hierarquia na matriz de sustentabilidade. Nele se encontram as organizações que procuram equilibrar as preocupações econômicas, sociais e ambientais, como apregoa o princípio do TBL proposto por

OS, Organizações e Sustentabilidade, 6(2), p. 42-58, Londrina, PR, jul./dez. 2018,

ISSN 2318-9223, http://www.uel.br/revistas/uel/index.php/ros/issue/view/1478/showToc 
Elkington (2011). As iniciativas deste nivel devem ir além da conformidade legal e do objetivo da lucratividade, como apresentado nos dois primeiros niveis (Van Marrewijk, 2010).

Nesta abordagem, questões como a importância do potencial humano, a responsabilidade social e os cuidados com o planeta devem ser consideradas nas decisões estratégicas. Assim, os principais valores abordados são consenso, prevenção de conflitos, trabalho em equipe, igualdade, participação, honestidade e transparência (Van Marrewijk, 2010).

Atendendo às orientações desta subcategoria, os respondentes foram questionados se as iniciativas sustentáveis da Itaipu vão além da conformidade legal e do objetivo da lucratividade. Inicialmente, o entrevistado / ressaltou que a usina não é orientada pelo lucro, pois "tem uma natureza jurídica diferenciada, onde precisa basicamente equilibrar custos e receitas" (Entrevistado J). No que é pertinente à legislação, "a Itaipu segue o Tratado da Itaipu, que é como se fosse sua própria lei. Então a gente diz que a Itaipu faz além da lei de forma voluntária" (Entrevistado J).

Os dados fornecidos pelos entrevistados coincidem com as informações obtidas no relatório de sustentabilidade de 2013, em que fica evidenciado que a usina realiza espontaneamente uma série de iniciativas que beneficiam a comunidade, uma vez que ela é regida por um tratado internacional e legalmente deve se submeter às exigências desse normativo:

\begin{abstract}
Desde a época da sua construção, a Itaipu realiza espontaneamente uma série de iniciativas que beneficiam a região oeste do Paraná e a população da Tríplice Fronteira (Brasil, Argentina e Paraguai). No planejamento e execução das ações, a empresa adota como referência diversos acordos, tratados e convenções nacionais e mundiais, como o Pacto Global das Nações Unidas e a Carta da Terra, e também busca cooperar com o fortalecimento das políticas públicas estabelecidas pelo Governo Federal para o enfretamento de problemas regionais (Itaipu, 2016a, p. 55).
\end{abstract}

Pode-se observar que os funcionários da Itaipu compreendem que as ações de sustentabilidade realizadas transcendem as exigências legais e o objetivo da lucratividade. $O$ entrevistado $F$ reforça:
.. eu sei que vão. Aliás, lucratividade aqui não é o objetivo. A empresa foi concebida para gerar energia a preço de custo para seus donos, com alguns benefícios financeiros definidos, e não para gerar resultado da forma clássica. 0 respeito mútuo a esse espírito de cooperação é o que viabiliza essa parceria entre dois países de dimensões tão distintas. (Entrevistado F)

Esclarecidos os aspectos de conformidade legal e do objetivo da lucratividade, foi verificado se a usina trata os aspectos sociais, ambientais e econômicos com equidade. Essa questão gerou divergência. Alguns entrevistados entendem que o aspecto ambiental se sobressai: "o ambiental é mais forte e recebe mais atenção, ou então explora melhor essa questão de comunicação" (Entrevistado J). Outros acreditam que seja o econômico: "eu defendo que o lucro que financia as benesses ambientais e gera excedente para os reinvestimentos econômicos. Abrir mão do lucro seria insano. A humanidade precisa fazer com que o lucro conviva com todo esse respeito que é a ética da sustentabilidade" (Entrevistado G). No entanto, mesmo com algumas opiniões diferenciadas, os funcionários entendem que a Itaipu promove ações nas três áreas do TBL.

Essa perspectiva é reforçada pelo entrevistado C, que comenta que é necessário um olhar mais aprofundado sobre as ações realizadas. Segundo ele, muitos programas classificados como ambientais também apresentam benefícios sociais e econômicos, e vice versa. Isso demonstra que os aspectos do TBL se inter-relacionam e se retroalimentam, sendo difícil dissociá-los um dos outros.

O entrevistado $G$ destacou que as organizações deveriam sair da ética de mercado (consumista, extrativista) para perseguir a ética da sustentabilidade, que preza pelo equilíbrio entre as dimensões. Essa opinião acompanha o pensamento de Elkington (2011), quando defende que a sociedade deve mudar a ênfase de crescimento econômico, geralmente o grande objetivo das organizações

OS, Organizações e Sustentabilidade, 6(2), p. 42-58, Londrina, PR, jul./dez. 2018, 
capitalistas, para desenvolvimento sustentável (com foco nas qualidades econômica, ambiental e social).

Por fim, o entrevistado / salienta que o tema é muitas vezes trabalhado de forma fragmentada, 0 que pode representar um desafio a ser superado:

\begin{abstract}
... um dos desafios que eu vejo seja tratar a sustentabilidade de maneira fragmentada. Por exemplo, na diretoria financeira, eles cuidam de coisas que entendem que seja da diretoria deles. Só que se eles ampliarem o olhar, vão ver que contribuem para o meio ambiente, contribuem para o social e talvez isso não esteja muito claro ainda. Com essa visão fragmentada se perde muito, eu acho (Entrevistado J).
\end{abstract}

Evidencia-se, por meio das respostas obtidas, que existem divergências de opiniões em relação à igualdade de importância com que são tratados os aspectos do TBL. Enquanto alguns acreditam que o ambiental seja o mais valorizado, outros consideram o econômico como o mais perseguido. No entanto, a maioria entende que a usina está no caminho do equilíbrio e apresenta preocupações sociais, ambientais e econômicas. Esse resultado também representa uma das principais críticas associadas à teoria da SO: a sua dificuldade de mensuração e operacionalização, ou seja, avaliar e quantificar quanto cada aspecto é trabalhado (Munck, 2013).

O entrevistado $F$ afirma que "hoje, já não é mais possivel delimitar as ações entre o que é sustentabilidade e o que não é, porque a transversalidade do conceito permeia todas as ações do plano operacional, que é o conjunto de tudo que a empresa executa no dia a dia". Assim, a partir das observações realizadas em campo e da análise das entrevistas, percebeu-se que a usina demonstra preocupação com três as dimensões a fim de cooperar com o desenvolvimento de médio e longo prazo. Embora seja difícil mensurar qual dos aspectos ganhe mais atenção, todos eles recebem iniciativas determinadas. Inclusive, a própria usina incentiva a transversalidade dos temas, em que uma área complemente a outra, reforçando a interconexão dos pilares. Cabe também destacar que a empresa em estudo objetiva o equilíbrio financeiro, e não o lucro, e que, desde o início de suas atividades, manifestou preocupação com o entorno.

Esses resultados denotam que a Itaipu Binacional está no nivel de sustentabilidade organizacional consciente e/ou conservadora, uma vez que atende aos requisitos propostos pela categoria. Concluída a análise do terceiro nível de SO, parte-se para a SO sinérgica.

\title{
Nivel de Sustentabilidade Organizacional Holistica
}

O nível de sustentabilidade organizacional holística é o quinto e último em hierarquia na matriz de sustentabilidade. Nele estão presentes as organizações em que a SO é integrada em todos os aspectos da organização, buscando contribuir para a qualidade e a continuação da vida, agora e no futuro. Ela considera que todos os seres e fenômenos são mutuamente interdependentes e que cada pessoa ou organização tem uma responsabilidade universal com os demais seres vivos (Van Marrewijk, 2010).

Os principais valores relacionados a esse nivel são: interdependência, preocupação com as gerações futuras, sabedoria, suficiência e vida responsável. No que é pertinente a esse aspecto, os respondentes foram indagados se consideram que cada pessoa e/ou organização tem uma responsabilidade universal para com os outros seres. De maneira geral, os entrevistados se mostram sensibilizados e mobilizados pelo tema. 0 entrevistado B acredita que seja necessário repensar a lógica capitalista da sociedade, voltada para o lucro, e considerar aspectos como preservação ambiental ao afirmar que "se todos pensassem que é preciso deixar de ganhar um pouco e pensar mais no ambiente, nós teríamos um planeta do futuro melhor (Entrevistado B).

OS, Organizações e Sustentabilidade, 6(2), p. 42-58, Londrina, PR, jul./dez. 2018, 
As organizações também podem contribuir com a resolução de problemas socioambientais das comunidades nas quais estão inseridas por meio da sua capacidade de fornecer recursos financeiros e humanos, inovação, infraestrutura, tecnologia e promoção de boa governança. Entende-se, assim, que a transição para a sustentabilidade exigirá a reestruturação das organizações, com stakeholders engajados em uma visão clara do futuro, atuando de maneira eficiente e eficaz nos três pilares do TBL (Blowfield, 2013; Elkington, 2011). Nesse sentido, o entrevistado I destaca o poder de influência que as empresas exercem por meio do seu poder financeiro e de decisão, ao orientar seus funcionários a agir de acordo com alguns pressupostos pré-determinados.

Essa conscientização a respeito da SO advém das prerrogativas da cúpula organizacional, a exemplo do diretor de coordenação da Itaipu Binacional, Nelton Miguel Friedrich, grande entusiasta do tema e que manifestou sua opinião em um paper interno:

\begin{abstract}
Daniel Goleman já disse: "Quanto mais sustentável, mais saudável e mais humano, melhor". Tudo porque, não há "plano B" para o nosso planeta. O consenso inédito entre países ricos, em desenvolvimento e pobres confirma tal imperativo. Temos que agir e podemos fazê-lo mudando o rumo em outra direção, que não o abismo. E fazê-lo de acordo com o pressuposto do ganha-ganha: ganha o planeta e ganham a natureza ("o cuidado com nossa casa comum"), a economia, o consumidor, a responsabilidade social e ambiental, o equilíbrio, a equidade, a transparência. Ganham a atual e as futuras gerações (Itaipu, 2016b).
\end{abstract}

Contata-se que as preocupações sociais, ambientais e econômicas são contínuas na organização, tanto que a empresa entende que as ações de hoje podem impactar a vida das futuras gerações. Assim, a usina trabalha a conscientização dos seus funcionários e da comunidade, para que ocorra uma transformação de valores, na qual cada indivíduo amplie seu olhar e passe a se responsabilizar pelo coletivo.

Diante das evidências apresentadas ao longo deste trabalho, infere-se que a empresa estudada atingiu o nível de SO holística, pois a SO já faz parte da cultura organizacional. Os valores da sustentabilidade já fazem parte do dia a dia dos colaboradores da empresa e também do relacionamento com seus stakeholders, a exemplo dos fornecedores, comunidades do entorno, clientes e opinião pública, entre outros. A usina também demonstra estar em constante aperfeiçoamento, além de incentivar as pessoas a incorporarem os princípios da sustentabilidade a fim de que as novas práticas se perpetuem.

Como forma de sintetizar os resultados encontrados, o Quadro 2 apresenta os níveis de sustentabilidade organizacional presentes na Itaipu Binacional:

QUADRO 2 - NIVEIS DE SO DA ITAIPU BINACIONAL

\title{
Niveis de sustentabilidade organizacional
}

\begin{tabular}{|c|c|}
\hline \multicolumn{2}{|r|}{ Niveis de sustentabilidade organizacional } \\
\hline 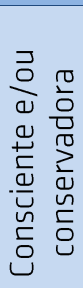 & $\begin{array}{l}\text { As ações de sustentabilidade realizadas transcendem as exigências legais e o objetivo da } \\
\text { lucratividade. } \\
\text { Existem divergências de opinião em relação à igualdade de importância com que são tratados os } \\
\text { aspectos do TBL; no entanto, a maioria dos entrevistados concorda que a empresa possui iniciativas } \\
\text { sociais, ambientais e econômicas. } \\
\text { Os aspectos do TBL se inter-relacionam e se retroalimentam, sendo difícil dissociá-los um dos outros. }\end{array}$ \\
\hline 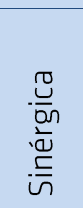 & $\begin{array}{l}\text { O compromisso com a sustentabilidade é uma tendência mundial. } \\
\text { O tema deve ser mais bem explorado para que os resultados positivos sejam maximizados. } \\
\text { Os funcionários reconhecem a sustentabilidade como crucial o sucesso organizacional. } \\
\text { O SGS proporciona discussões internas sobre os aspectos da sustentabilidade, proporcionando assim } \\
\text { atualizações contínuas as práticas organizacionais. }\end{array}$ \\
\hline
\end{tabular}

OS, Organizações e Sustentabilidade, 6(2), p. 42-58, Londrina, PR, jul./dez. 2018, 


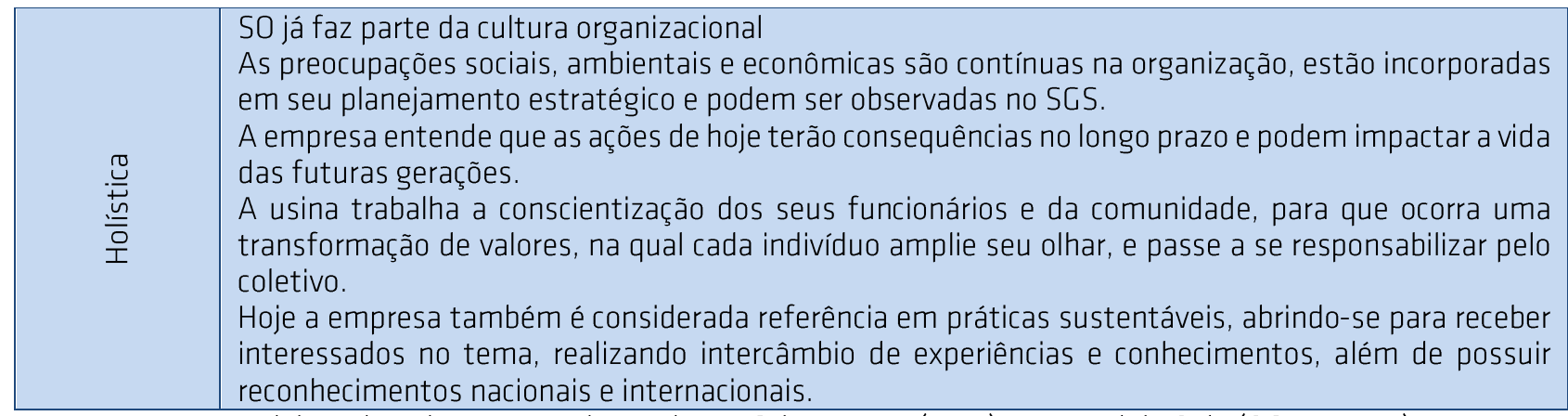

Fonte: Elaborado pelos autores, baseado em Schumpeter (1985) e Manual de Oslo (OCDE, 2005).

A matriz de sustentabilidade proposta por Van Marrewijk (2010) permitiu identificar que a Itaipu Binacional se encontra no nivel de SO holística, considerados os três últimos niveis: SO consciente e/ou conservadora, SO sinérgica e SO holística. Pode-se observar que a Itaipu desenvolveu iniciativas coerentes com o seu planejamento estratégico, alinhando missão, visão e políticas aos valores institucionais. O nível de SO alcançado representa que a empresa possui uma complexidade diferenciada das demais, mas não significa, necessariamente, que é mais eficiente em suas ações (Van Marrewijk \& Werre, 2003).

As iniciativas adotadas pela Itaipu têm proporcionado premiações nacionais e internacionais, entre eles a do programa Cultivando Água Boa, eleito a melhor prática em gestão de recursos hídricos do mundo; ganhou ainda o prêmio Água para Vida, concedido pela ONU. Na premiação do complexo turístico Itaipu, foi a única empresa brasileira vencedora na categoria pesquisa, tecnologia e inovação do prêmio de Excelência e Inovação do Turismo, concedido pela Organização Mundial do Turismo. Obteve também a Certificação Life, que atesta a eficiência do sistema de gestão ambiental e as ações para a conservação da biodiversidade (Itaipu, 2016a). Assim, a empresa é considerada referência em práticas sustentáveis e se abre para receber interessados no tema, realizando intercâmbio de experiências e conhecimentos, incentivando a continuidade de suas ações.

\section{CONSIDERAÇÕES FINAIS}

Este estudo teve o objetivo de compreender o nivel de sustentabilidade organizacional na Itaipu Binacional. Tal constatação foi realizada por meio da observação não participante, entrevistas semiestruturadas, análise documental e diário de pesquisa. Os resultados apontam que a usina foi classificada no nível de SO holística, quinto e último em hierarquia na matriz de sustentabilidade proposta por Van Marrewijk (2010). Esse resultado demonstra a complexidade organizacional, com uma estrutura organizacional ancorada em sistema de gestão de sustentabilidade que integra a 50 em todos os contextos organizacionais e níveis hierárquicos, favorecendo a qualidade da vida no longo prazo.

O estudo também apontou que a SO desempenha papel fundamental na estratégia organizacional da empresa, confirmando seu compromisso com a responsabilidade social, respeito ao meio ambiente e crescimento econômico. Essa aderência foi verificada pela adequação da missão, visão e políticas alinhadas com os valores propostos, além de um portfólio de ações sociais, ambientais e econômicas que subsidiam as mudanças.

Destaca-se que as iniciativas adotadas pela Itaipu são de caráter voluntário, uma vez que ela é regida por um tratado internacional e obedece a um sistema de gestão diferenciado, devendo se submeter às exigências desse normativo. No entanto, as ações da usina procuram estar alinhadas às obrigações previstas na legislação brasileira e paraguaia e envida esforços para atender os requisitos previstos em tais legislações em todas suas unidades operacionais (entrevistado J). Assim, a usina se sobressai pela promoção de iniciativas sustentáveis, servindo de inspiração para que empresas

OS, Organizações e Sustentabilidade, 6(2), p. 42-58, Londrina, PR, jul./dez. 2018,

ISSN 2318-9223, http://www.uel.br/revistas/uel/index.php/ros/issue/view/1478/showToc 
nacionais, internacionais e a comunidade com a qual se relaciona assumam uma postura mais ética e responsável nos negócios, contribuindo com a qualidade econômica e socioambiental para as futuras gerações.

Neste contexto, faz-se necessário salientar as principais contribuições para a empresa pesquisada. Ao identificar o nivel de $\mathrm{SO}$ em que a empresa se encontra, é possivel auxiliar gestores e pesquisadores a compreender como a aderência organizacional às demandas sociais pode favorecer o reconhecimento organizacional perante a sociedade.

A pesquisa também identificou sugestões para a usina. Observou-se que alguns funcionários não compreendem como suas atividades diárias impactam nos resultados organizacionais. Assim, entende-se que a consciência organizacional pode ser mais bem trabalhada, para que a cultura da sustentabilidade seja internalizada por seus membros, além de que as práticas de 50 devem ser cultivadas diariamente para que os resultados positivos sejam contínuos.

Para a academia, entende-se que o tema abordado é de relevância para fortalecer a literatura acerca dos temas SO, uma vez que o estudo sobre a matriz de sustentabilidade permitiu compreender em que nivel de $\mathrm{SO}$ a usina se encontra, além de ampliar a discussão desta temática, que é considerada uma tendência pela sociedade.

Alguns aspectos podem ser considerados como limitantes do desenvolvimento desta pesquisa, destacando-se que os estudos de caso podem não permitir generalização científica (Yin, 2010). Nessa perspectiva, este trabalho se restringe a um único caso, que é descrito a partir da visão dos entrevistados e, assim, dados importantes podem ter sido omitidos. A questão temporal também é considerada, uma vez que foram investigados acontecimentos passados e dependeu da capacidade de os indivíduos recordarem fatos que ocorreram anteriormente. Tanto que Martins (2004) esclarece que, entre o momento passado e o presente, é possivel que a memória do informante tenha sofrido interferências de suas experiências.

Recomenda-se a aplicação deste estudo em outras organizações públicas e privadas, como em outros ramos de atuação, de modo que se possam corroborar ou não os resultados encontrados nele. Acredita-se, ainda, que seja pertinente a realização de estudos quantitativos com maior número de participantes, proporcionando amplitude ao contexto estudado, uma vez que foram entrevistados indivíduos que trabalham com a sustentabilidade, retratando suas percepções da organização e do ambiente. Também se recomenda a realização de uma pesquisa longitudinal para verificar se os resultados encontrados se alteram com o tempo.

Por fim, consoante às discussões proporcionadas pelo trabalho, sugere-se a seguinte reflexão: a Itaipu Binacional não é pressionada economicamente, ou seja, não objetiva o lucro, pois a tarifa cobrada referente ao valor unitário do serviço de eletricidade deve ser suficiente para cobrir todos os seus custos e, desta forma, ela dispõe de recursos para promover a sustentabilidade. Mas em um contexto em que a empresa é pressionada economicamente, as questões de responsabilidade socioambiental serão priorizadas quando os acionistas almejam maximizar o lucro?

\section{REFERÊNCIAS}

Aneel (2016). Capacidade de geração do Brasil. Recuperado de: <http://www2.aneel.gov.br/aplicacoes/capacidadebrasil/capacidadebrasil.cfm>.

Babin, B., Hair Jr., J. F., Money, A. H., \& Samouel, P. (2005). Fundamentos de métodos de pesquisa em administração. Porto Alegre: Bookman.

Bardin, L. (2016). Análise de conteúdo. (3ª reimp. da $1^{\text {a }}$ edição). Lisboa: Edições 70.

OS, Organizações e Sustentabilidade, 6(2), p. 42-58, Londrina, PR, jul./dez. 2018,

ISSN 2318-9223, http://www.uel.br/revistas/uel/index.php/ros/issue/view/1478/showToc 
Bauer. M. W., \& Gaskell, G. (orgs.). (2015). Pesquisa qualitativa com texto, imagem e som: Um manual prático (13. ed.). Petrópolis: Vozes.

Braga, C., Silva, P. P., \& Santos, A. (2015). Level of disclosure of environmental information in the electricity sector: An empirical study of Brazil and Iberian Peninsula. Global Journal of Management and Business Research, 15(9), 39-53.

Blowfield, M. (2013). Business and sustainability. Oxford: UK.

Borca, C., Maria, L., Sirbu, R., \& Fistis, G. (2015). Corporate sustainability perspective in the context of a multi-level stakeholder management. Joint International Conference 2015. Recuperado de: <http://www.toknowpress.net/ISBN/978-961-6914-13-0/papers/ML15-223.pdf>

Carvalho, A. C. V., Stefano, S. R., \& Munck, F. (2015). Competências voltadas à sustentabilidade organizacional: Um estudo de caso em uma indústria exportadora. Cestão \& Regionalidade, 31(91), 33-48.

Denzin, N. K., \& Lincoln, Y. S. (2006). O planejamento da pesquisa qualitativa: Teorias e abordagens (2. ed.). Porto Alegre: Artmed.

Dyllick, T., \& Hockerts, K. (2002). Beyond the business case for corporate sustainability. Business Strategy and the Environment, 11, 130-141.

Elkington, J. (2011). Canibais com garfo e faca. São Paulo: Makron.

Filho, A. P. A., Sedor, R. W. R., Finck, A., \& Asanome, C. R. (2011). Estudo de caso do Programa Cultivando Água Boa: Resultados, modelo de gestão e o seu papel como referência mundial. ISAE/FGV.

Garrido, G., \& Saltorato, P. (2015). Isomorfismo, eficiência simbólica e legitimidade social na institucionalização da sustentabilidade socioambiental nas organizações contemporâneas. Perspectivas em Gestão; Conhecimento, 5(2), 69-82.

Hopwood, B., Mellor, M., \& O’Brien, G. 2005. Sustainable development: Mapping different approaches. Sustainable Development, 13(1), 38-52.

Itaipu (2016a). Relatório de Sustentabilidade 2015. Recuperado de: <https://www.itaipu.gov.br/pdfviewer.html?file=RS2015_030816_2.pdf\&titulo=Relat\%C3\%B3rio \%20de\%20Sustentabilidade\%202015>.

Itaipu (2016b). Estamos no limite: A maior crise da história da humanidade e a Agenda 2030 localglobal. Recuperado de: <https://www.itaipu.gov.br/sala-de-imprensa/positionpapers/estamosno-limite-maior-crise-da-historia-da-humanidade-e-agenda-203>.

Martins, H. H. T. de S. (2004). Metodologia qualitativa de pesquisa. Educação e Pesquisa, São Paulo, 30(2), 289-300.

Munck, L. (2013). Gestão da sustentabilidade nas organizações: Um novo agir frente à lógica das competências. São Paulo: Cengage Learning.

Orsato, R. J. (2012). Estratégias de sustentabilidade: Quando vale a pena ser verde?(Tradução: Sérgio A. Rosenvald). Rio de Janeiro: Qualitymark Editora.

Porter, M. E., \& Kramer, M. R. (2006). Estratégia \& sociedade: 0 elo entre vantagem competitiva e responsabilidade social empresarial. Harvard Business Review Brasil, 84(12), 78-92.

Sachs, I. (2008). Desenvolvimento: Includente, sustentável, sustentado. Rio de Janeiro: Garamond.

Soparnot, R. (2011). The concept of organizational change capacity. Journal of Organizational Change Management, 24(5), 640-661.

OS, Organizações e Sustentabilidade, 6(2), p. 42-58, Londrina, PR, jul./dez. 2018, 
Stefano, S. R., \& Alberton, A. (2015). Competências para sustentabilidade e governança nas cooperativas agroindustriais: Uma proposta de análise. Anais XXXIX EnANPAD, 1. p. 1-16.

Van Marrewijk, M. (2010). The Cubrix, an integral framework for managing performance improvement and organisational development. Journal of Technology and Investment, 1(1), 1-13.

Van Marrewijk, M., \& Werre, M. (2003). Multiple levels of corporate sustainability. Journal of Business Ethics, 4(2-3), 107-119.

Yin, R. K. (2010). Estudo de caso: Planejamento e métodos (4. ed.). Porto Alegre: Bookman.

World Commissionon Environmentand Development (1987). Our common future. Oxford: Oxford University Press. 